\title{
ALGUNAS REFLEXIONES ACERCA DE UN POSIBLE PROCESO DE REINSTITUCIONALIZACIÓN EN LAS INSTITUCIONES DE LA EDUCACIÓN SUPERIOR SOME IDEAS ON A POSSIBLE PROCESS OF RE-INSTITUTIONALIZATION IN HIGHER EDUCATION INSTITUTIONS
}

\author{
Alejandra Capocasale Bruno'
}

\section{RESUMEN}

Toda sociedad que se precie de ser democrática atiende la Educación Superior como bien social y público en tanto derecho humano. Resulta clave comprender que es la que desliga al sujeto educando del pasado tradicional y fijo y conduce hacia una emancipación por la cual los sujetos se religan a partir de sus propias preguntas antropológicas, su ser en el mundo, sus pulsiones con lo universal cultural. La forma escolar en el siglo XXI es altamente compleja y diversa. No obstante, persiste dentro de una forma tradicional que permanece de manera hegemónica dentro de un orden social occidental en constante cambio. La Educación Superior es el espacio educativo donde se debería plasmar un proceso de reinstitucionalización de la institución educativa democrática e inclusiva como proyecto social y colectivo.

Palabras clave: Educación Superior-Democracia-Socialización inclusiva

\section{ABSTRACT}

Any society that prides itself on being democratic treats Higher Education as a social and public good as a human right. It is key to understand that it is the one that separates the educating subject from the traditional and fixed past and leads him towards an emancipation by which the subjects are linked from their own anthropological questions, their being in the world, their drives with the universal cultural. The school form in the 21st century is highly complex and diverse. Nevertheless, it persists within a traditional form that remains hegemonic within a constantly changing Western social order. Higher Education is the educational space where a process of re-institutionalization of the democratic and inclusive educational institution as a social and collective project should take shape.

Keywords: Higher Education-Democracy-Inclusive Socialization.

\section{INTRODUCCIÓN}

Este artículo tiene como objetivo presentar un análisis contextualizado de una visión innovadora de la práctica educativa en la Educación Superior dentro del marco de la estructura social moderna occidental actual. Actualmente continúa vigente un modo de producción capitalista como modelo hegemónico a nivel económico, social, político y cultural que trasciende fronteras por un proceso de globalización que

1 Directora del Instituto de Perfeccionamiento y Estudios Superiores “Juan E. Pivel Devoto" (IPES) del Consejo de Formación en Educación (CFE) de la ANEP. Profesora de Filosofía (IPA). Licenciada y Magíster en Sociología (Facultad de Ciencias SocialesUdelaR). Diploma y Especialización en Gestión Educativa (FLACSO Argentina). E-mail: alecapocasale@gmail.com 
permite su reproducción y lo fortalece. Esta estructura social moderna occidental se caracteriza por estar en permanente cambio. Este devenir que se ha caracterizado como acelerado, cíclico e irrefrenable tiñe tanto el contexto global como los contextos locales. Dentro de estos contextos se instala la práctica educativa institucionalizada, formal de la Educación Superior. Esta praxis implica interacciones sociales, vínculos sociales, intercambios entre sujetos generándose un gran entramado de relaciones e interacciones sociales. El análisis que se presenta en este artículo es en clave institucional de la Educación Superior, considerando las relaciones e interacciones sociales que se enmarcan y posicionan desde ese espacio formal. Tal como lo establece Durkheim (1997, p. 31): "En efecto, sin desnaturalizar el sentido de este término, se puede llamar institución a todas las creencias y todos los modos de conducta instituidos por la comunidad...." Las instituciones son la base sustantiva del entramado social pues representan la posibilidad de génesis y el funcionamiento de los hechos sociales en tanto maneras de ser, hacer, pensar, y sentir (Durkheim, 1997). A su vez, vinculado al concepto de institución educativa interesa otro concepto articulador: la solidaridad social.

En las sociedades modernas occidentales actuales la solidaridad social se manifiesta a nivel orgánico funcional. Esto significa que las relaciones e interacciones sociales se generan y articulan a partir de funciones sociales. Los vínculos entre los sujetos están constituidos y sostenidos principalmente por las funciones que cumplen y el lugar dentro de la estructura social que ocupan. Los roles sociales se han convertido en una de las formas de expresión social de las relaciones humanas emergentes de la práctica educativa. El capitalismo de la mano de la globalización del siglo XXI ha ido paulatinamente desdibujando al sujeto humano como tal en cuanto centro de la práctica educativa. En la actualidad, las interacciones sociales situadas institucionalmente se han ido convirtiendo en expresión de un vacío que refleja los procesos de deshumanización. Los procesos de fragmentación social y de exclusión han generado que las instituciones educativas se conviertan en uno de los espacios más de deshumanización. Lo que ocurre a nivel de la sociedad, resulta visible en la institución educativa. Se podría afirmar que las prácticas educativas que ocurren tienden a estar teñidas por la razón instrumental y han perdido en su espacio la sensibilidad del reconocimiento de la condición humana. Las instituciones educativas de Educación Superior no están siendo ajenas a este proceso. Están pasando a ser un espacio de reflejo de desigualdades sociales instaladas a todo nivel y cuya reproducción se expresa en procesos de estratificación social. El resultado: un sujeto que a pesar de que ha alcanzado llegar al nivel educativo de la Educación Superior, en su contemporaneidad,

10 | se encuentra invisibilizado y no conocedor de sus derechos humanos. En este contexto, resulta relevante el re-pensar la práctica educativa institucionalizada en la Educación Superior. Ya no es suficiente con esgrimir el argumento de que el acceso a este nivel educativo representa un logro educativo y social en sí mismo. El sujeto educando alcanza este nivel dentro del sistema educativo, pero ¿qué ocurre cuando ingresa? ¿Hasta qué punto el acceso a la Educación Superior garantiza que el sujeto educando logre religar con el mundo que lo rodea? ¿De qué forma la práctica educativa en la Educación Superior lo conecta y vincula con un mundo que da cabida a los conceptos que son la base de procesos de democratización: derechos humanos, inclusión y justicia social? ¿En la Educación Superior se abre el sentido de una solidaridad social acorde a los tiempos que se viven de forma contextualizada? Por lo menos, la práctica educativa institucionalizada formal tendría que comenzar a agendarse como una oportunidad histórica de encuentro entre sujetos adultos pensantes para la reconstrucción de un nuevo proceso de humanización. El Estado, como agente social activo por excelencia, tendría que llevar adelante este cambio social a través de una propuesta política-programática que genere una política educativa humanizadora-humanizante y fortalecedora de una nueva democracia para este nuevo contexto social.

\section{LA NECESIDAD DE UNA NUEVA PRÁCTICA EDUCATIVA SOCIALIZADORA EN LA EDUCACIÓN SUPERIOR}

Se puede afirmar que el contexto es uno de los principales condicionantes de la realidad socioeducativa tanto a nivel local como global. La globalización ha ido entretejiendo lazos de necesidades creadas que se presentan como modelo hegemónico de lo que tendría que enseñarse en una institución educativa. En la Educación Superior se han impuestos tipos de curriculum, dispositivos de enseñanza y de aprendizaje, estrategias didácticas y hasta un vocabulario que articula toda planificación didáctica. Esta suerte de imposiciones se presenta con sutileza pedagógica, sin fundamentación teórica profunda o con meras justificaciones técnicas que se repiten de forma continua. Desde el punto de vista epistémico se puede establecer que existe un presupuesto que está presente en las prácticas educativas y que las tiñe de tal forma que las condiciona: considerar que la educación es un fenómeno y proceso de carácter individual. El individuo es 
presentado como el primer beneficiario de la educación. Cabe aclarar que desde una perspectiva inicial de ninguna manera se puede afirmar que esta perspectiva individual de las funciones de la educación es incorrecta. Todo lo contrario. Se pueden mencionar entre sus funciones individuales: promover el desarrollo de la personalidad de los sujetos, colaborar con la adaptación individual al medio de pertenencia a través de la transmisión de conocimientos, valores, normas e inclusive el buen manejo del lenguaje. Sin embargo, todo proceso educativo es esencial y sustantivamente social. Es imposible concebir un sistema educativo que no se relaciona con una sociedad contextualizada. La educación se presenta como un fenómeno histórico y situado. Todo sistema educativo implica instituciones educativas, legislación educativa, actores sociales involucrados y muchos componentes más que distan de tener cualidad abstracta. Los mismos están presentes en el marco de la realidad social. Lo educativo no es una entelequia y no debería considerarse como tal. El sistema educativo es parte de una estructura social que se reproduce y perdura en el tiempo. Con claridad meridiana, el pedagogo Dewey (1971) expresa que toda sociedad existe mediante un proceso de transmisión que se realiza por medio de la comunicación, maneras de ser, hacer, pensar y sentir de las generaciones adultas a los más jóvenes. Sin esta comunicación, la vida social no lograría perdurar en el tiempo. Él considera que la educación es la que, a través de la comunicación, genera que la sociedad continúe existiendo, sino que también es la construye el todo social. De allí que afirme que existe un estrecho vínculo entre los conceptos de común, comunidad y comunicación.

El todo social requiere para su permanencia en el tiempo a la educación, y esta está presente en forma continua a lo largo de toda la vida del sujeto. El sujeto social transita por la vida configurando su ser con y a través de una educación que puede tener una índole más o menos sistemática (educación formal, informal y no formal). En este artículo el interés se centra en la educación de tipo formal que es la que tiene como propiedad más visible su carácter sistemático y que, se manifiesta en una institucionalización organizada de manera burocrático-administrativa. Se pone el énfasis, específicamente, en la práctica educativa dentro de la institución educativa formal. Meirieu (2004), ante este escenario educativo de reproducción social y cultural tradicional, desarrolla el proceso de ruptura necesario dentro del marco de una sociedad democrática que genera la práctica educativa para los sujetos educandos. Él considera que en la práctica educativa se da una transmisión de saberes que ligan al sujeto al mundo al que pertenece. Al mismo tiempo lo desligan del pasado tradicional y fijo. Los sujetos se interrogan, se desprenden, construyen una mirada crítica y nueva. Tomando estos conceptos para el análisis se puede establecer que específicamente, a partir de la práctica educativa los sujetos educandos en la Educación Superior pueden llegar a religarse (momento inseparable de los anteriores: ligarse-religarse) reuniendo sus propias preguntas antropológicas, su ser en el mundo, sus pulsiones con lo universal cultural. El acceso a las instituciones de Educación Superior es relevante pues les otorga a los sujetos educandos una oportunidad para "religarse" dentro del mundo que los rodea, con los otros y con ellos mismos. Es evidente que no es suficiente con el ingreso a este nivel educativo. Se requiere que transiten por él de forma consciente y comiencen a generar rupturas de conceptos epistémicos sustantivos y estructuradores de su ser: por ejemplo, dejar de percibir lo espacial y lo temporal como irreversible y lineal ascendente. El tiempo ya no es concebido sobre un modelo evolucionista, sino que ha alcanzado el nivel de poli temporalidad que introduce la complejidad de los sucesos y la incertidumbre. El espacio ya no es más vivido como ajeno y separado del sujeto. Las relaciones sociales se dan en interacciones sociales (relaciones-interacciones sociales) que se inscriben en flujos irreversibles que ligan-desligan-religan a los sujetos con ellos mismos, su contexto y los otros. La forma escolar en el siglo XXI es altamente compleja y responde a los principios estructuradores que Morin (2004, p. 1) describe en su "epistemología de la complejidad" introduciéndola con la frase: "La cuestión de la complejidad, jes compleja!". Esta realidad de la complejidad que se impone aún no logra la aceptación del ámbito académico y de la sociedad toda. A pesar de que al paso del tiempo han surgido iniciativas que han intentado crear entre otras tantas innovaciones: instituciones educativas no graduadas, flexibilizar la organización de tiempos y espacios escolares, integrar disciplinas, organizar trabajos en equipo, la forma escolar tradicional "ha demostrado ser notablemente duradera" (Tyack y Cuban, 2001). El problema central es que cada vez la forma escolar está más alejada y ajena a las características de un orden post-tradicional no aceptándose que la tradición se ha agotado como principio regulador de la pedagogía -más allá de su valor histórico sustantivo. El sujeto se construye y reconstruye de forma constante en una sociedad que le exige tomar decisiones sobre la base de la incertidumbre y el cambio constante. La forma escolar en la Educación Superior, como marco en el cual se lo socializa para el mundo del trabajo y su ser en el mundo, no le brinda herramientas teórico-prácticas para ello. En la institución educativa el sujeto realiza un proceso de ligar con normas y valores tradicionales que se le inculcan a partir de ritmos de trabajo racionalmente organizados y espacios claramente definidos. Cuando el sujeto sale al mundo ese marco espacio-temporal no está presente. Asimismo, la pedagogía tradicional ha ido perdiendo legitimidad en el discurso hegemónico de los 
otros agentes sociales que no están involucrados con el sistema educativo formal (familia, políticos, medios de comunicación, pares, entre otros). El mensaje es confuso y confunde. La forma escolar permanece. El orden social ha cambiado. El sujeto se encuentra solo y no logra ligar con su cultura, los otros y ni siquiera consigo mismo. El sujeto educando que asiste a las instituciones educativas de la Educación Superior es adulto, por lo tanto, consciente de su elección educativa. Esto no lo exime de caer en confusiones acerca de su elección de carrera o de opción laboral. A esta confusión se le suma el nuevo papel de las técnicas y su transformación de lo espacio-temporal. Stiegler $(2002$, p. 109) explica claramente que las técnicas ya no son objeto externo del hombre y por lo tanto herramental inerte que éste domina. Las técnicas tienen existencia propia, su historia. Estas han logrado tener un lugar en el mundo del sujeto que llega al punto de la dependencia psicoafectiva. Esto se agudiza a en un capitalismo pulsional que gesta sujetos que tienen un deseo no colmado constante que los presiona. La técnica se ha colocado al servicio de las pulsiones que exigen la no postergación de los deseos. Se ha perdido la fase reflexiva de la acción. Esto tiene consecuencias directas en la forma escolar y obviamente en las prácticas educativas. Los sujetos educandos perciben el ritmo temporal de las instituciones educativas como lento y denso en el proceso de toma de decisiones. El espacio escolar es percibido como aburrido y como carente de suficiente animación interactiva. Los tiempos y espacios escolares construidos para la reflexión ni siquiera son comprendidos por los educandos. No los ocupan. No los disfrutan. Representan lo que Augé (1998) denominó "no lugares": espacios de tránsito en los que el sujeto no siente compromiso ni ligazón alguna. Menos aún, espacios para "desligar y religar"a decir de Meirieu (Southwell, 2006, p. 5).

Ante esta realidad socioeducativa, el camino propuesto es volver a recordar el valor de lo colectivo en y desde la práctica educativa. Lo colectivo, que trasciende positivamente lo individual (más allá de complementarlo e implicarlo) tiene un poder coercitivo sobre el sujeto educando que está presente en toda institución educativa. El sujeto educando que ingresa a una institución de Educación Superior ya tiene un recorrido por la educación primaria y secundaria. Este sujeto ha ido construyendo y reconstruyendo su identidad y sus relaciones con el mundo y con los otros a través de su trabajo escolar. Este trabajo escolar es productivo pues construye su identidad individual y también su identidad colectiva. Tal como lo explica Puiggrós (1990, p. 29) la educación es "una práctica social compleja, no solo la aplicación de metodologías y técnicas". Esto se genera a partir de condiciones de producción internas al proceso productivo. En este sentido, 12 | es necesario recuperar la categoría sujeto. Según Puiggrós (1990, p. 30), la educación es una práctica de mediación productora de sujetos por otros sujetos. El "sujeto pedagógico" es un emergente del encuentro entre el educador y el educando en situaciones educativas diversas. La forma escolar tradicional disciplinó sujetos a lo largo de la historia: los normalizó y los socializó bajo la justificación de la urgencia de la integración social. En este momento socio-histórico las características de esta nueva sociedad post-industrial del siglo XXI interpela ese proceso. Meirieu le dice a Birgin (2012, p. 7) en su entrevista:

Se trata de cómo movilizar a un sujeto para que se apropie de la cultura, y cómo hacer para que la cultura lo emancipe y a su vez le permita entrar en lo colectivo. Como dice Edgar Morin, la educación es hacer lazo entre una historia singular y una cultura que la preexiste: ese lazo moviliza el deseo y el mismo es constitutivo de la cultura. Porque una cultura viva es, para mí, aquella que re-liga lo íntimo con lo universal.

Se hace presente el concepto de deseo como aquel que hace que el sujeto reconozca su necesidad de tener un espacio que habitar y un tiempo en el cual transcurrir, crecer y aprender (Meirieu, 1997, p.101). Esta mediación pasa a ser sustantiva para lograr que el vínculo entre las prácticas educativas y la sociedad no se rompa. De esta forma, Meirieu le da uno de los sentidos fundamentales cuando dialoga con Birgin (2012, p. 9) al trabajo pedagógico: "...sobre el encuentro entre un sujeto y una cultura, se interroga sobre los valores implícitos de lo que se trama en el acto de enseñar, sobre el proyecto de hombre y de sociedad que está en juego". A partir de este concepto es que en la institución educativa de Educación Superior sería plausible volver a considerar el tiempo y el espacio escolares en la práctica educativa: el planteo de este pensador de la necesidad de reconfigurar la escuela como un lugar de "desaceleración en un mundo de aceleración" es central. La forma escolar requiere organizarse bajo el lema de que hay que tener tiempo para pensar (Birgin, 2012, pp 12-13):

El desafío entonces es reinstitucionalizar la escuela hasta en su arquitectura (...) Ahora bien, si reinstitucionalizar la escuela implica acondicionarla para suscitar posturas de trabajo intelectual, es esencial entonces rematrizar el tiempo y el espacio, estructurar colectivos, instituir rituales capaces de soportar la mirada atenta e incitar la intención de aprender. 
El espacio y el tiempo escolares como estructuradores de una nueva posible la forma escolar. En ellos y a través de ellos se entreteje la solidaridad social de lo colectivo en y desde la práctica educativa institucionalizada. Es un entramado fundamental que según Meirieu (2006), hay que reconstruir, reconfigurar, contextualizándolo al siglo XXI. Se requiere trabajar pedagógicamente desde una práctica educativa socializadora que trascienda los carburantes básicos de la sociedad actual occidental: el interés económico, la pulsión inmediata, y el consumismo exacerbado individual. La satisfacción personal de deseos individuales deja de lado el Bien común colectivo. De alguna forma, es comprensible que el proyecto educativo esté en crisis, pues "la educación es aprendizaje para la renuncia a la omnipotencia" (Meirieu, 2006, p. 4). El educador es quien conduce al sujeto por, hacia y en la espera de su deseo contenido. Es quien lo lleva a entender que es necesario aplazar el pasaje al acto. Es necesario meditar acerca del acto que se va a cumplir y sus consecuencias no solo personales sino colectivas. Este proceso Meirieu $(2006$, p. 5$)$ lo describe como el pasaje de la renuncia a lo infantil hacia el estado adulto que implica acceso al estado ciudadano:

Por eso es que la educación y la democracia se inscriben en el mismo movimiento: es la renuncia al narcisismo. Educar a un chico es ayudarlo a renunciar a su narcisismo y educarnos como pueblo democrático es educarnos para renunciar cada uno de nosotros a nuestros intereses individuales, para reflexionar acerca de lo que podría ser el bien común y el interés colectivo. En una democracia la escuela no es otra cosa que el lugar de proyección posible del aprendizaje de la democracia, justamente.

La pedagogía del siglo XXI en la Educación Superior es central. Su relevancia tiene que ver con tener lugar en la obra colectiva social. No se puede ocupar todo el lugar todo el tiempo. No se puede hacer varias elecciones simultáneas o pasar de opción en opción de carreras o de opciones laborales pues eso implica no estar en lugar alguno y caer en un vacío temporal sin sentido. El lugar se ocupa y el tiempo se transita a través del sentido y compromiso con un proyecto colectivo que une y que no reniega de la norma, sino que la integra como estructuradora de lo social. Ahora bien, ¿cuáles son las posibilidades reales que tiene esta propuesta de reinstitucionalización de la institución educativa de Educación Superior?

\section{ENTRE POSIBILIDADES Y REALIDADES}

Rancière (2003, p. 23) escribe: "Toda la práctica de la enseñanza universal se resume en la pregunta: ¿qué piensas tú? Todo su poder está en la conciencia de emancipación que actualiza en el maestro y suscita en el alumno". La clave está en un proceso de emancipación en el que el sujeto no queda a la deriva como ser pensante. Resulta fácil enunciar: hay que re-institucionalizar la institución educativa; lo difícil es hacerlo. Las instituciones educativas de Educación Superior tienen su historia, sus rituales-marco, sus normas y valores, su estructura jerárquica con roles claramente definidos a partir de status otorgados por merecimiento académico individual. Es decir, que están organizadas racionalmente y burocráticamente de acuerdo a un modelo de gestión que les ha permitido sobrevivir a los tiempos vividos institucionalmente y sociales. Los rituales pedagógicos estructuran la práctica educativa con los espacios y tiempos escolares. Todos estos elementos han ido constituyendo las identidades institucionales y sus sentidos y misiones en el mundo académico de la Educación Superior. Por este motivo, merecen el respeto en toda propuesta innovadora. Las instituciones de Educación Superior pueden cambiar sin ser lo que son y han sido en su historia. La propuesta es que siendo lo que son se abran a la posibilidad de ser algo nuevo acorde a los tiempos de una modernidad occidental que requiere sujetos que dentro de la incertidumbre puedan construirse como seres pensantes individuales y colectivos a la vez. De alguna forma esta propuesta convoca a fortalecer el papel de las instituciones de Educación Superior colaborando con un proyecto de la universalidad que tiene que ver con una sociedad democrática. La democracia requiere que en las prácticas educativas que se producen en la Educación Superior se genere una organización del trabajo que desarrolle lo colectivo (sin dejar de lado lo individual) de forma tal que los sujetos educandos no sientan un vacío existencial a partir de sus elecciones de carrera o de opciones laborales. Lo colectivo se construye como proyecto social y político en el que la institución educativa y los sujetos que participan de y en ella tienen un papel fundamental. La "polis" se construye y reconstruye desde las instituciones educativas. La Educación Superior es un eslabón clave para un proceso de construcción de un colectivo solidario que posibilitará la continuidad temporal y espacial. La institución educativa de Educación Superior en una sociedad democrática debería ser un lugar de los encuentros y desencuentros, de lo que une y separa a la vez, transforma en público por imposición o porque se ponga a disposición: requiere construcción. La institución educativa pasa a ser "espacio público" cuando los sujetos están dispuestos al compromiso de su producción por el "bien común" (Meirieu, 2004, 
pp. 50-51). Este "bien común" no es espontáneo, también se define a través de un proceso colectivo. La institución educativa que nos llega desde el siglo XX y se viven el siglo XXI, no es la misma del fermental origen del siglo XIX, ni en su fundamento, sus características, su funcionamiento, sus fines, sus amenazas, sus riesgos, ni en los sujetos que la integran. No obstante, su fin último- el proceso de socialización de los sujetos para la construcción de ciudadanía- permanece. Este fin está íntimamente relacionado con el pensar de los sujetos. Un pensar que contiene la tensión social entre lo individual y lo colectivo. Un pensar que no puede quedar en los intereses personales, sino que debería transitar hacia el Bien Común de lo colectivo dentro de una sociedad democrática. Un pensar que requiere una nueva forma escolar de Educación Superior. Es tiempo de reflexionar acerca del nuevo papel de la práctica educativa en las instituciones de Educación Superior como marco básico para el desafío de un nuevo proceso democratizador.

\section{REFERENCIAS}

Augé, M. (1998). Los no lugares. Espacios del anonimato. Una antropología de la sobre modernidad. Barcelona, España: Gedisa.

Birgin, A. (2012). Entrevista a Philippe Meirieu. Revista No 30 del Instituto de Investigaciones en Ciencias de la Educación. Buenos Aires: F.F. y L. UBA. DOI: http://dx.doi.org/1034096\%2Friice.n30.141

Dewey, J. (1971). Democracia y Educación. Buenos Aires, Argentina: Losada.

Durkheim, E. (1997). Las reglas del método sociológico. México D.F., México: Fondo de Cultura Económica.

Meirieu, Ph. (1997). Aprender sí. Pero ¿cómo? Barcelona, España: Octaedro.

Meirieu, Ph. (2004). En la escuela hoy. Barcelona, España: Ediciones Octaedro.

Meirieu, Ph. (2006). El significado de educar en un mundo sin referencias. Conferencia en MECyT, 27 de junio, Buenos Aires, Argentina, pp. 1-11. Recuperado de:http://www.me.gov.ar/curriform/publica/meirieu final.pdf

Morin, E. (2004). La epistemología de la complejidad. Gazeta de Antropología, №20, pp. 1-12. Recuperado de:

http://museoarqueologico.univalle.edu.co/imagenes/investigacion\%20y\%20creacion/Morin-Edgar\%20Epistemologia\%20de\%20la\%20Complejidad-Edgar\%20Moran.pdf

Puiggrós, A. (1990). Sujetos, Disciplina y Curriculum en los orígenes del sistema educativo argentino. Buenos Aires, Argentina: Galerna.

Rancière, J. (2003). El maestro ignorante. Cinco lecciones sobre la emancipación intelectual. Barcelona, España: Laertes.

Southwell, M. (2006). El escenario educativo para las nuevas generaciones. Conferencia en La Mutua de Philippe Meirieu, Buenos Aires, 26 de junio, Revista Explora. Programa de Capacitación Multimedial, MECyT, Buenos Aires, Argentina, p. 5. Recuperado de:

http://www.slideshare.net/EscuelaBicentenario/docentes-la-tarea-de-cruzar-fronteras-y-tender-puentes

Stiegler, B. (2002). La técnica y el tiempo. Tomo I: El pecado de Epimeteo. Hondarribia, España: Hiru.

Tyack, D. y Cuban, L. (2001). En busca de la utopía. Un siglo de reformas de las escuelas públicas. México D.F., México: Fondo de Cultura Económica.

Fecha de recepción: 25/10/2019

Fecha de aceptación: 27/11/2019 